\title{
Relationship Between Self-efficacy and Chinese Language Speaking Anxiety of International Students at Northeast Normal University
}

\author{
Huma Akram ${ }^{1 *} \quad$ Muhammad Junaid $^{2,1}$ Yang Yingxiu ${ }^{3}$ \\ 1.Faculty of Education Northeast Normal University Changchun China \\ 2.Professor, faculty of Education Northeast Normal University Changchun China
}

\begin{abstract}
:
The existing research was conducted in order to explore the correlation between Self-efficacy and Chinese Language Speaking Anxiety among International students at NENU, Changchun, China. In that respect the intention of this survey is to probe whether international students' Chinese Language Speaking Anxiety reveal significant variation with respect to gender, Nationality, Time lived in China, Number of Chinese Courses learned and Frequency of communication with Chinese friends in Chinese language. The research group involved 131 international students i.e. $(70$ males $=53 \%$ and 61 females $=47 \%)$ from NENU. The study employed the quantitative method conducted through surveys by adapted questionnaires developed by Horowitz's (1986) and Graumer Erickson, A.S.,Soukup, J.H.,Noonan, P.M., \&McGurn, L.(2016). The data were examined by means of independent T-test, one-way ANOVA and Pearson's correlation approaches. T-test reveals high degree of Chinese Language Speaking Anxiety among international students but found no any considerable distinction in terms of gender. While ANOVA results show a only significance difference between the numbers of Chinese courses the participants learnt. In last A Pearson's $r$ data revealed a weak positive association between Self-efficacy and Chinese Language Speaking Anxiety among International students at NENU.
\end{abstract}

Keywords: Self-efficacy, Chinese Language Speaking Anxiety

DOI: $10.7176 / \mathrm{JEP} / 10-2-04$

\section{Introduction:}

Higher education study in a foreign country is become a common practice whether the study is for short time, for example, for a few months to gain intercultural familiarity or for long-time, for example, to pursue an educational degree. The numbers of international students in different countries are different with increasing or decreasing digits (Andrade, 2006). International students are those students who spend their time momentarily in the foreign country for the sake of international educational exchange (Talebloo\&Baki, 2013). While according to Prudence, Amy and S (2012) an international student is the one, who spend all or some part of his/her higher academic time in a country rather than his/her native one. As China is playing a primary role in the worldwide integration of higher education and world economy, a worldwide interest and significance of Chinese language learning is increasing day by day. In regards to its writing i.e. character-based and speaking is based on different tones, Chinese language is considered as the most complex foreign language for most international students, which may cause higher level of speaking anxiety among them.

\subsubsection{Foreign language Speaking Anxiety:}

Anxiety can be referred as a mental situation of nervousness, an uncertain phobia obliquely related to anything (Scovel, 1978). From several studies it has been identified that around one-third students of foreign language experience to somewhat a mild degree of speaking anxiety (Horwitz, 2001), which affects negatively on foreign language learning ( Luo, 2013). Out of four language skills, speaking has been observed most anxiety provoking skill (Luo, 2015). Anxiety, related to the affective domain, mostly seen in speaking classes (Gardner \&MacIntyre; MacIntyre, 1993)

\subsubsection{Self-efficacy:}

Belief of individuals about their own competence for handling and operating a particular task is referred to Selfefficacy (Bandura, 1997).

According to various studies anxiety is influenced by ones' perceived self-efficacy, i.e.

Self-efficacy beliefs play an integral part in the managing and directing anxiousness state. ((Zimmerman, 1999; Bandura, 1994; Usher \& Pajares, 2008).

Self-efficacy is commonly interrelated with certain emotional problems, including anxiety disorders (Bandura, 1997). Thus, these two variables seem inter-related to each other.

However various studies have been carried out regards to investigate the association between perceived self-efficacy and non-native language speaking anxiety, but it's not rich in context to Chinese as a foreign language. Hence this study is intended to explore the correlation between Self-efficacy and Chinese Language Speaking Anxiousness among International students at NENU, beside this, wishing to offer some useful recommendations for Chinese language teachers and for future research. 


\subsection{Background of the Study}

The studies on anxiety are broadly characterized by three types, i.e. characteristic anxiety, anxiousness associated with any situation, and state anxiety (see Cattell \& Scheier, 1963; MacIntyre \& Gardner, 1989, 1991; Spielberger, 1966). General affinity to getting anxious in a large number of situations refers to Trait anxiety (Spielberger, 1983). As trait anxiety has become attribute of one's being, on that ground it is persistent with time. Putting it differently, trait anxiety makes people nervous at many different occasions and situations. While State anxiety related to worried or nervous emotion which usually occurs at a specific state under specific conditions (Spielberger, 1983) and mostly go along with physical indications like diaphoresis, sweaty palms, dryness of mouth, muscular compressions and stain, and fast heartbeat. State anxiousness is not persistent as it is expected to alter in different situations. The 2 nd type of anxiety, i.e. situation-associated anxiety, might be observed as a characteristic anxiety confined with a certain setting' (MacIntyre \& Gardner, 1991). This type is identical to trait anxiety in that sense that it may be consistent to some occasions but not persistent in diverse situations, such as giving evaluation, speaking in public, anticipation in class, communication with foreign person in non-native language, resolving health problems. For account of such features MacIntyre and Gardner (1991) imply that "foreign language anxiety should be studied with situation specific measures. According to Horwitz et al. (1986) foreign language classroom anxiety is a typical situation-specific anxiety and separated from other kinds of anxieties.

Horwitz, Horwitz, and Cope (1986) observed foreign language anxiety as "“"a diverse complex set of selfperceptions, thinking, feelings, and behaviors related to classroom language learning arising from the uniqueness of the language learning process" (p.128). Their determined three kinds of anxieties linked to non-native language anxiety, helps in assisting foreign language teachers and students in understanding about foreign language anxiety. 1-Communication anxiety (McCroskey, 1970), 2- Negative assessment fear (Watson \& Friend, 1969), and 3- test anxiety (Sarason, 1978). They also offered a tool to evaluate foreign language anxiousness, named as Foreign Language Classroom Anxiety Scale (FLCAS).

By means of this tool researchers were able to investigate the Foreign Language anxiousness, efficiently. (e.g. Aida, 1994; Horwitz, Horwitz \& Cope, 1986; Horwitz, 2001; Le, 2004 found the ratio with mild degree of foreign language anxiety, i.e. around one third among students. Furthermore, few studies explored constant temperate negative link among foreign language anxiousness and its accomplishment (Horwitz, 2001).

Tsai in 2013 finds a negative association among foreign language anxiety and self-efficacy. While, Tuncer's study in 2016, identified an affirmative association between educational self efficacy and foreign language anxiousness.

As far as Chinese language is concerned, due to its complexity it is considered as the most challenging language for international students. The Foreign Service Institute (FSI) has classified foreign languages into four kinds on the basis of their difficulty level. According to which, the languages that are not taught usually includes, Chinese, Korean, and Arabic graded as category IV and need to take much time to reach at level 2 proficiency (Walker, 1989). Due to high complexity of Chinese language may cause anxiety among learners of Chinese (Luo, 2012). Specifically Chinese is based on tonal variations, which need extra attention and may cause anxiousness among CFL learners. However rare studies are found regarding link within Self-efficacy and foreign language anxiousness, but no any exclusive study is found related in context to Chinese language speaking anxiety.

\subsection{Setting of the Study:}

The current study was conducted in Northeast Normal University, Changchun, China. This University is one of the top ranked normal universities of higher education, administrated by the Ministry of Education. It was established by Communist Party of China in 1946, considered as the first inclusive institution. Its name was redefined to Northeast Normal University based on the national objectives in 1950. The university is placed in the capital of Jilin Province i.e. Changchun, and covers an area of around 1,670,000 square meters. The university is divided into two campuses, i.e. Main campus positioned at Renmin Street and Jingyuetan campus in Jingyuetan Tourism Development Zone. The total number of existing students at NENU is 24,567, comprise of 14,365 undergraduates, 9,478 M.A. and Ph.D. students, and 724 foreign international students. The university is embraced by number of qualified foreigners and Chinese experts and scholars, including 381 professors, 462 associate professors and $276 \mathrm{PhD}$ supervisors (http://en.nenu.edu.cn/nenu/overview.php).

NENU has successively established exchanging relations with more than 200 overseas universities and research institutions in over 40 countries and regions. Since 1950s, NENU has received almost 10,000 international students from more than 90 countries and regions (http://www.csc.edu.cn/studyinchina/universitydetailen.aspx?collegeId=12).

\subsection{Problem Statement:}

Though the past literature regarding relationship between self-efficacy beliefs and foreign language anxiety is very limited but shows diverse results. 
Some studies (Tsai, 2013; Noghabi, 2012; ErkanandSaban, 2011; Çimen, 2011; Anaydubalu, 2010; GhonsoolyandElahi, 2010; Mills et al., 2006; Cheng, 2001; MacIntyre et al., 1997) show that there is a negative correlation between self-efficacy beliefs and foreign language anxiety.

While others (Tuncer 2016 ) show positive correlation self-efficacy beliefs and foreign language anxiety.

On the other side certain studies claim that there is no connection between students' English self-efficacy beliefs and their foreign language anxiety (Feryal, 2008). Furthermore, there are a few studies (Tahmassian and Moqaddam, 2011; Marashi, 2015) on the relationship between language self-efficacy and anxiety and claim that the correlation between the two variables vary in language context. In spite of all this scarce studies, no any empirical studies are found on the relationships between Chinese as a foreign language speaking anxiety and self-efficacy together. This made us curious to conduct this study.

\subsection{Objectives}

The objectives of the study are:

(i) To determine the level of students' Chinese language speaking anxiety.

(ii) To investigate the relationship between students' perceived academic self-efficacy beliefs and Chinese language speaking anxiety.

(iii) To determine whether perceived academic self-efficacy beliefs and Chinese language speaking anxiety of the students differ significantly with respect to gender or not.

\subsection{Significance}

As inferred from the problem statement, the association between level of self-efficacy and foreign language speaking anxiety of students become visible to be an important subject in speaking foreign language.

It can also facilitate the language teachers in developing a better understanding about their students psychologically and will suggest techniques to boost students' learning of foreign language.

\subsection{Research Questions}

1. What is the level of Chinese language speaking anxiety of international students?

2. Do perceived academic self-efficacy beliefs and Chinese language speaking anxiety of the students differ significantly with respect to gender?

3. Is there a significant relationship between students' perceived academic self-efficacy beliefs and Chinese language speaking anxiety?

\section{Review of Literature}

Learning a foreign language not only represent cognitively as well as become an affective feature for the learner. Anxiety has been observed the most common issue in in the learning of non-native language practice. This problem is generally observed in communication classes (Gardner \&MacIntyre ; MacIntyre, 1993), where students put lingual intake and generate their views at the same time (Harmer, 2004). These problems made several researchers to investigate about this problem and find out its solutions. Furthermore studies have revealed its negative influence of language anxiety over learning efficiency and communication capability and researchers are still trying to find out solutions to reduce its effect in language classrooms.

In accordance with Horwitz's perception, several empirical studies have been carried out on Foreign Language speaking Anxiety (FLSA) that is the most general problem faced by the students in communication classes of language. Few studies appear to be identical findings, while some have shown diverted results in terms of Foreign Language speaking Anxiety. Öztürk (2009) carried out a qualitative analysis to figure out causes of foreign language speaking anxiety and students' thoughts in Turkey. According to findings students undergo a small degree of speaking anxiety; however, interviews revealed that according to the majority of the students, verbal communication skill is the main factor of creating anxiety.

\subsection{Foreign language anxiety:}

Different perceptions are found in literature regarding anxiety. But the most familiar one was presented by Spielberger in1983, i.e. Anxiety is explained as an unappealing psychological state, characterized by the feelings of stress and nervousness.

Verbal communication learning anxiety may be encountered because of lingual complexities in foreign language that learners have to face while learning the target language (Hashemi andAbbasi, 2013). However, Horwitz (2001) claimed that foreign language anxiety is independent of first language learning disabilities and should be viewed as an important factor that hinders language learning in and of itself. Zhang and Zhong (2012) have categorized causes of foreign language learning anxiety as being 1 -student originated, this type of anxiety is triggered within learner himself. 2-academic associated, it is linked with academic environment, e.g., classroom 
3-expertise specific, this is associated with any particular kind of skill

4-Community enforced, this is caused due to obligatory social rules, orders or customs.

Young (1990) specified about foreign language anxiety as it is a sophisticated and multidirectional mechanism. MacIntyre and Gardner (1993) further explained it as the prejudiced sensation of nervousness and uneasiness particularly related with non-native language perspective, tends to appear during communication, listening and learning.

In line with statement of Horwitz et al. (1986), anxiety associated with one's thoughts, emotions and reactions during foreign language learning, is referred as foreign language anxiety. He also presented a theory related to language learning anxiety, comprises of three interconnected elements i.e. 1- communication anxiety is characterized by a fear or shyness with regards to communicate with others. 2- Adverse assessment phobia that is related to the anxiety regarding being tested or evaluated by others and 3- Test anxiety demonstrate a fearful performance leading to phobia of loosing.

This illustration was followed by several studies. According to Horwitz's (2001) inference, individuals, with high anxiety level, affect their academic performance in a negative way, and obtained low scores, while the students with least degree of anxiety obtained good scores. Moreover, Saito and Samimy (1996) study also reveal that foreign language anxiety may cause a reverse influence on learners' achievement. While according to Aida (1994), learning of foreign language is affected in a negative way by foreign language anxiety.

Nikolov and Djigunovi'c (2006) conducted a diverse study according to which high levels of speaking anxiety can speak small amount of verbal communication in foreign language. With the passage of time speaking skill have become the most interesting skill of language skill to be investigated, and got most attention

\subsection{Foreign language speaking anxiety:}

Uneasy state of mind or nervousness among students is generally observed in foreign language learning environments. It's also been identified by number of studies.

In present time, foreign language learning mostly takes place through oral exercises in front of the class or in the form of group discussions. Such kind of oral tasks in foreign language may affect the students badly due to which they may feel anxious while speaking (Tanveer, 2007). As stated by Young (1990), anxiety triggered, among most of learners is due to the foreign language speaking. In addition, Palacios (1998) study also revealed that communication is considered as the main factor that causes anxiety among students.

Several investigations have been done on account of anxiety among students of foreign language. In line with his study, Price (1991) explored that learners were been observed conscious and nervous during pronunciation of foreign language, particularly in front of their observers, as speaking is considered as the most nervousness causing activity.

Related to communication some other activities are also considered as a cause of nervousness, such as according to Koch and Terrell (1991), anxiety causing factors are mainly involved by spoken activities, acting in front of peers and explanation of terms.

In addition some studies were conducted in line with the perspective of teachers and learners in order to attain deeper understanding. Saltan (2003) found a low level of spoken anxiety among students of foreign language. Furthermore, Balemir (2009) gave attention on the correlation between expertise rank and level of foreign language spoken anxiety in term of English language as a foreign perspective. As per findings, students of foreign language in Turkish University encounter mild level of communication anxiety.

Additionally, few studies identified that anxiety is observed more, when the students are asked to present a speech in front of public with no any preparation, by Ay (2010).

Some scholars seemed curious regarding influence of gender in terms of learning of foreign language progression. According to Betters (1986), Balemir (2009), Csizer and Dornyei (2005), explorations, it was identified that, gender has got a considerable part with regards to foreign language speaking anxiety

\subsection{Gender and Foreign Language Anxiety:}

McLean \& Anderson (2009) also explored the association between gender and second language learning anxiety, as per findings it was identified that females possesses more fear as compare to men that leads to generate anxiety among them. Despite that the revealed findings couldn't find any significant correlation between gender and their rate of performance, and found uncertain results (Matsuda \&Gobel, 2004).

There are many factors that influence the process of learning second or foreign language, and anxiety is considered one of the most affective factors in this regard. The investigation of the effectiveness of anxiety was realized in the early of the 1970 s in the western countries and there are many studies that were carried out to investigate foreign language anxiety such as (Chastain, 1975; Bailey, 1983).

An important point must be taken into consideration is that there are many factors that affect the relationship between foreign language anxiety and gender. Among these factors are reading habit, the use of the strategies of learning, motivation, the students' beliefs concerning learning, and the level of proficiency. Green 
and Oxford (1995) investigated the relationship between gender and foreign language strategies and the result showed that females who are foreign language learners tend to use more strategies during the process of learning.

However, a study by Wicks-Nelson \& Israel (2006) found that naturally, female feel more anxious than male. This is due to many factors such as confidence, proficiency (Bruce et. al, 2005), security, and superiority. Under certain circumstances, female tend to feel easily vulnerable and therefore lead to the feeling of anxious and worried while male on the other hand does obtain more self-control and ability to detach themselves from unpleasant feelings. On a similar vein, from a study conducted by Machida (2001), she examined FL Japanese language class anxiety based on gender differences and the findings reflected that female learners are more anxious that the male counterparts.

Some researchers have looked into the correlation between gender and second and foreign language anxiety. McLean \& Anderson (2009) also indicate that female have greater fear and have high possibility to develop anxiety as compared to men. However, findings on the relationship between learners difference in gender with their performance, anxiety level and understandings in learning L2 and FL remain inconclusive and debatable (Matsuda \&Gobel, 2004).

According to Rosenfeld \&Berko (1990), different gender does not affect the communication apprehension as they claimed that 'gender is not significant in communication anxiety'. Although males tend to be shyer while female tend to have more public speaking anxiety, there seem to be a few consistent differences between the genders.

However, a study by Wicks-Nelson \& Israel (2006) found that naturally, female feel more anxious than male. This is due to many factors such as confidence, proficiency (Bruce et. al, 2005), security, and superiority. Under certain circumstances, female tend to feel easily vulnerable and therefore lead to the feeling of anxious and worried while male on the other hand does obtain more self-control and ability to detach themselves from unpleasant feelings. On a similar vein, from a study conducted by Machida (2001), she examined FL Japanese language class anxiety based on gender differences and the findings reflected that female learners are more anxious that the male counterparts.

On the contrary, Kitano (2001), in his research in the context of English as a foreign language found that in comparison to female students, male students tend to be more anxious while learning a second language. The data shows that male students are found to be more apprehensive in speaking as they perceive their speech to be less competent than that of the females.

\subsection{Self- efficacy:}

Self-efficacy refers to one's belief and confidence in one's ability to accomplish a specific task or mastery of a particular task or activity (Bandura, 1994).

The ideas presented so far and the findings of the research into relationship between perceived academic self-efficacy and foreign language speaking anxiety might help language teachers gain a better understanding of the reasons underlying their students' different language learning outcomes and thus may help them find ways to enhance students' learning of foreign language. Hence, the relationship between perceived academic selfefficacy levels and foreign language speaking anxiety of students appears to be a significant variable in speaking foreign language.

\section{Methodology:}

\subsection{Design of the study:}

The design of the study was a quantitative survey which was sought through the adapted questionnaires examining a possible correlation between the perceived academic self-efficacy beliefs and Chinese language speaking anxiety of international students.

\subsection{Participants:}

All The participants of the study were the international students of NENU. Since the whole population was unapproachable for gathering data therefore simple random sampling technique was used to represent the whole population and 131 participants were selected randomly from all the schools/departments of the NENU, out of which 61 were females $\& 70$ were males.

\subsection{Research Instruments:}

The two questionnaires were adapted in order to measure both variables that are:

1-Horwitz's (1986) Foreign Language Speaking Anxiety Scale

This scale consists of 33 statements, each to be rated by the respondent on a 1 (no anxiety) to 5 (high anxiety) Likert scale. Out of 33 items, 19 statements were directly related to Chinese language speaking anxiety. While levels of Chinese Language Speaking Anxiety are divided into two levels which are high and low. The high level of anxiety is determined from the mean value between " 3.01 to 5.00" while the low level is taken from the 
range of 1.00 to 3.00 .

Item numbers $2,5,8,11,14,18,22,25,28$, and 32 were reverse scored.

Language speaking anxiety questionnaire was found to be highly reliable (19 items; $\alpha=.82$ ).

2-Self-Efficacy Questionnaire (2016 version) by Graumer Erickson, A.S.,Soukup, J.H.,Noonan, P.M., \&McGurn, L.(2016) was used.

The questionnaire comprised of 13 items made on a 5-point, Likert-type scale. This scale ranges from 1 (Not very like me) to 5 (Very like me). The self-efficacy questionnaire was found to be highly reliable (13 items; $\alpha$ $=.96)$.

\subsection{Data Analysis}

Distribution of questionnaires among students was carried out personally by researcher. Collected data was analyzed statistically through different tests i.e. Mean, Independent $t$ test, One-way ANOVA. After checking and coding the data, seven participants' data were excluded from the analysis because of their missing data and identifiable pattern of answers. All the findings are mentioned in the following tables

Table 1: Level of Chinese Language Speaking Anxiety

\begin{tabular}{|l|l|l|l|l|c|}
\hline Variable & N & Minimum & Maximum & Mean & SD \\
\hline Anxiety & $\mathbf{1 3 1}$ & $\mathbf{1 . 9 5}$ & $\mathbf{4 . 4 2}$ & $\mathbf{3 . 1 9}$ & $\mathbf{5 8}$ \\
\hline
\end{tabular}

According to the findings in table 1 the mean of Chinese Language Speaking Anxiety is 3.19, which shows high level of anxiety as the high level of anxiety is determined from the mean value 3.01 to 5.00.

Table 2: T-test analysis for Chinese Language Speaking Anxiety according to Gender.

\begin{tabular}{|l|l|l|l|l|l|}
\hline Gender & $\mathrm{N}$ & Mean & SD & T & P \\
\hline Male & 70 & 3.17 & .53 & .610 & .292 \\
\hline Female & 61 & 3.22 & .63 & & \\
\hline
\end{tabular}

According to table 2 there is no any significant difference between male and female participants in displaying Chinese language speaking anxiety. This finding is in line with Feryal's (2008) study, which yields no significant difference between girls and boys in terms of anxiety level (For girls the means are 101.16, for boys it is 101.75 .)

Table 3: Factors Associated with Chinese Language Speaking Anxiety

\begin{tabular}{|l|l|l|l|l|l|l|}
\hline S.No & Variables & Sum of Sq & Df & M.Sq & F & Sig. \\
\hline 1. & Nationality & 1.200 & 2 & .600 & 1.800 & 1.69 \\
\hline 2. & Time lived in China & 1.427 & 2 & .713 & 2.512 & .120 \\
\hline 3. & Number of Chinese Courses taken & 4.740 & 7 & .677 & 2.129 & .045 \\
\hline 4. & Frequency of communicating with Chinese friends & 1.205 & 2 & .602 & 1.807 & .168 \\
\hline
\end{tabular}

To check whether participant's nationality, time lived in China, number of Chinese courses learned, and frequency of communication with Chinese friends in Chinese language was significantly associated with Chinese language speaking anxiety or not, a between-groups ANOVA was performed.

Participant's number of Chinese courses taken was found only significantly associated with Chinese language speaking anxiety among international students, i.e. $F(7,123)=2.129, \mathrm{p}<.05$, While other variables were not significantly related to Chinese language speaking anxiety.

Table 4: Correlations between Self-efficacy and Chinese Language Speaking Anxiety.

\begin{tabular}{|l|l|l|l|}
\hline Variables & Mean & SD & Status \\
\cline { 1 - 2 } Self-efficacy & 3.85 & 1.014 & $\mathrm{r}(131)=0.24, \mathrm{p}>0.05$ \\
\cline { 1 - 2 } Language Anxiety & 3.20 & .580 & \\
\cline { 1 - 2 }
\end{tabular}

In order to find out the relationship between Self-efficacy and Chinese Language Speaking Anxiety, Pearson's correlation test as performed, which revealed a weak positive correlation between self-efficacy and Chinese language speaking anxiety i.e. $r=0.24$.

This finding is compatible with Tuncer (2016) study which found that academic self-efficacy affected foreign language classroom anxiety in a positive way $(\beta=, 30 ; \mathrm{p}<.05)$.

\section{Conclusions}

This study investigated the relationship between perceived academic self-efficacy and Chinese language speaking anxiety (CLSA) among international students of NENU, and also the level of anxiety across various variables. The relationship and levels of self efficacy and (CLSA) were identified by the use of adapted questionnaire.

Finally it can be concluded that there is high level of Chinese language speaking anxiety among international students and (CLSA) is a separate phenomenon and found no any correlation between self efficacy and Chinese language speaking anxiety. To conclude, the following points have been highlighted from the analysis of the data; 
That there is no effect of gender in terms of (CLSA), found no any significant difference between male and female participants.

Participant's nationality, duration of being in China, and frequency of communication with Chinese friends has got no any impact on Chinese language speaking anxiety..

Significant difference was found between number of Chinese courses taken by the participants and (CLSA). Students who took least courses have high level of speaking anxiety then those who took less number of courses.

\section{Suggestions}

This study focused only one skill i.e. speaking anxiety, Future studies should be conducted on other three skills namely, listening, reading and writing, whether the four skills are equally anxiety-provoking.

The current study revealed high level of Chinese language speaking anxiety among international students, so in order to minimize anxiety, researchers should explore the sources of CLSA, by conducting in depth interviews from learners.

Chinese language course should be made compulsory for at least two initial semesters, in order to attain improvements in Chinese language proficiency in international students, and hence to minimize anxiety level.

In order to eliminate uncomfortable exposure in Chinese class, Chinese instructor should focus on students' emotions and avoid anxiety stimulating activities, like asking questions in front of class etc.

\section{Refrences}

Aida, Y. (1994). Examination of Horwitz, Horwitz, and Cope's construct of foreign language anxiety: The case of students of Japanese. Modern Language Journal, 78, 155-168.

Cattell, R. B. and Scheier, I. H. (1963). Handbook for the IPAT anxiety scale (2nd ed.). Champaign, IL: Institute for Personality and Ability Testing.

Chastain, K. (1975). Affective and ability factors in second language acquisition. Language Learning, 25, 153 161.Gardner, R. C. (1985). Social psychology and second language learning: The role of attitudes and motivation. London: Edward Arnold.

Horwitz, E. K. (2001). Language anxiety and achievement. Annual Review of Applied Linguistics, 21, 112-126.

Horwitz, E. K., Horwitz, M. B. and Cope, J. (1986). Foreign language classroom anxiety. Modern Language Journal, 70, 125-132.

Kleinmann, H. H. (1977). Avoidance behavior in adult second language acquisition. Language Learning, 27, 93107.

Luo, H. (2011). Construction of a Chinese as a foreign language (CFL) anxiety scale: towards a theoretical model of foreign language anxiety. Unpublished doctoral dissertation, University of Texas at Austin.

Luo, H. (2013a). Chinese Language Learning Anxiety and its Associated Factors. Journal of Chinese Language Teachers Association, 48 (2), 109-133.

Luo, H. (2013b). Foreign Language Anxiety: Past and Future. Chinese Journal of Applied Linguistics, 36 (4), 442-464.

MacIntyre, P. D. \& Gardner, R. C. (1994). The subtle effects of language anxiety on cognitive processing in the second language. Language Learning, 44, 283-305.

Watson, D. \& Friend, R. (1969). Measurement of social-evaluative anxiety. Journal of Consulting and Clinical Psychology, 33, 448-457.

Zhao, A. \& Whitchurch, A. (2011). Anxiety and its Associated Factors in College-level Chinese Classrooms in the U.S. Journal of Chinese Language Teachers Association, 46 (3), 21-47.

Chang Tsai (2013) The Impact of Forgein language anxiety, Test Anxeity, and Self-Efficacy Among Senior High School Students In Taiwan, Vol.1, No.3, pp.1-17, 